\title{
Prospective $\mathrm{CO}_{2}$ Saline Resource Estimation Methodology: Refinement of Existing US-DOE-NETL Methods Based on Data Availability
}

\author{
Angela Goodman ${ }^{\mathrm{a}} *$, Sean Sanguinito ${ }^{\mathrm{a}}$, Jonathan S. Levine ${ }^{\mathrm{a}}$ \\ ${ }^{a}$ United States Department of Energy, National Energy Technology Laboratory, P.O. Box 10940, \\ Pittsburgh, Pennsylvania 15236
}

To be submitted to: International Journal of Greenhouse Gas Control as an article

* Corresponding author. Tel.: 1-412-386-4962; Fax: 1-412-386-5870.

E-mail address: angela.goodman@ netl.doe.gov

Key words (4-6): $\mathrm{CO}_{2}$ resource estimation; $\mathrm{CO}_{2}$ sequestration; geologic storage; saline formations; data availability 


\begin{abstract}
Carbon storage resource estimation in subsurface saline formations plays an important role in establishing the scale of carbon capture and storage activities for governmental policy and commercial project decision-making. Prospective $\mathrm{CO}_{2}$ resource estimation of large regions or sub-regions, such as a basin, occurs at the initial screening stages of a project using only limited publicly available geophysical data, i.e. prior to project-specific site selection data generation. As the scale of investigation is narrowed and selected areas and formations are identified, prospective $\mathrm{CO}_{2}$ resource estimation can be refined and uncertainty narrowed when site-specific geophysical data are available. Here, we refine the United States Department of Energy National Energy Technology Laboratory (US-DOE-NETL) methodology as the scale of investigation is narrowed from very large regional assessments down to selected areas and formations that may be developed for commercial storage. In addition, we present a new notation that explicitly identifies differences between data availability and data sources used for geologic parameters and efficiency factors as the scale of investigation is narrowed. This $\mathrm{CO}_{2}$ resource estimation method is available for screening formations in a tool called $\mathrm{CO}_{2}$-SCREEN.
\end{abstract}




\section{Introduction}

Since 2007, the United States Department of Energy - National Energy Technology Laboratory (US-DOE-NETL) Carbon Storage Program and the Regional Carbon Sequestration Partnerships (RCSPs) have developed a series of Carbon Atlases approximately biannually (USDOE-NETL, 2007, 2008, 2010, 2012, 2015). Within each Carbon Atlas, prospective $\mathrm{CO}_{2}$ storage resources are quantified for the United States and parts of Canada and Mexico. As stated in the first Carbon Atlas (US-DOE-NETL, 2007), “The purpose of storage estimates developed using these methodologies is to provide a high-level inventory of the subsurface volume to store $\mathrm{CO}_{2}$ in the United States and Canada. This information can be used by the general public, elected officials, and planners." Goodman et al. (2011) presented the US-DOE-NETL $\mathrm{CO}_{2}$ storage resource estimation methodologies and methods for deep saline formations, depleted conventional oil and gas reservoirs, and unmineable coal seams, and Levine et al. (2016) presented a methodology for shale formations. Methods, their updates, and the overall methodologies are also contained in the Carbon Atlases, with revisions being adopted as improvements are made to reduce uncertainties in resource estimation. Extensive information regarding carbon storage practices can also be found in the US-DOE-NETL Carbon Storage Best Practices Manuals (US-DOE-NETL, 2013). Other groups such as the Unites States Geological Survey (USGS) and Carbon Sequestration Leadership Forum (CSLF) have also presented $\mathrm{CO}_{2}$ storage assessment methods (Bachu, 2008; Zhou et al., 2008; Burruss et al., 2009; Brennan et al., 2010; Szulczewski et al., 2012; Blondes et al., 2013).

The US-DOE-NETL resource estimation methodology for saline formations uses a volumetric-based approach, whereby the maximum available pore volume is calculated from known or estimated geologic and reservoir parameters. This initial volume is then reduced by 
applying efficiency factors to represent practical and physical limitations, e.g. unfavorable geology or uncertainties in multiphase transport processes (Goodman et al., 2011). An efficiency factor is applied to gauge the fraction of the total pore volume that will be accessible to $\mathrm{CO}_{2}$ storage.

The US-DOE methods are intended for application by interested users globally, and are therefore purposefully relatively simple. At initial stages of exploration of large regions or subregions, such as a sedimentary basin, prospective resource estimation relies on limited or unavailable geologic data. Therefore, assumptions must be made regarding formation and petrophysical properties either from sparse geophysical data or by extrapolation from regional or national data. As the scale of investigation is narrowed down to a selected area that might be developed for commercial storage, more detailed geologic characteristics of the target storage formation may become available. These higher resolution geologic data provide the opportunity to refine prospective storage estimates and reduce associated uncertainty. A comparison study showed that uncertainties in geological properties cause greater impact on prospective storage resource estimates than the choice of estimation method (Goodman et al., 2013). Other research groups have worked to refine prospective storage estimates when detailed geologic properties are available and identified a need for procedures to reduce uncertainty in storage estimates as more geologic data are available (Frailey and Finley, 2009; Ellett, 2013; Liu et al., 2013; Peck et al., 2014). Currently no method or standard exists that quantifies and reduces uncertainty that comes with increased geological data as prospective storage resource is refined from large regional or sub-regional assessments to selected area or specific site assessments (Goodman et al., 2011; Blondes et al., 2013). 
In this paper, we first provide an overview of the US-DOE-NETL saline resource estimation methodology for screening potential regions and sub-regions. Then, we emphasize how the availability of geologic data changes the choice of datasets used to generate petrophysical parameters and efficiency factor values. These underlying principles are then used to present refinements and improvements to the existing methodologies for prospective resource estimation. Specifically, we refine the United States Department of Energy - National Energy Technology Laboratory (US-DOE-NETL) methodology as the scale of investigation is narrowed from very large regional assessments down to selected areas and formations that may be developed for commercial storage. In addition, we present a new notation that explicitly identifies differences between data availability and data sources used for geologic parameters and efficiency factors as the scale of investigation is narrowed. Finally, this refined $\mathrm{CO}_{2}$ resource estimation method is made publicly available in a tool named $\mathrm{CO}_{2}$-SCREEN to calculate prospective $\mathrm{CO}_{2}$ storage resource (Sanguinito et al., 2016).

\section{Data Availability and Scale of Investigation}

Screening methods for large regions or sub-regions, such as a sedimentary basin, are designed to produce likely estimates of storage resource that are needed for broad energy-related requirements and climate stabilization (Bachu, 2015). As estimates are further refined based on improved geologic interpretation, resource assessments should progress from coarse volumetric screening approaches towards more precise numerical-based modeling to predict $\mathrm{CO}_{2}$ storage resource. This is analogous to the methodology process used by the oil and gas industry. Gorecki et al. (2015) also advised parallels with the oil and gas industry for refining storage estimates. Initial $\mathrm{CO}_{2}$ storage efficiency factors for regional scale assessments are designed to 
produce most likely estimates for the total region being assessed and are then refined as specific subsets of the total region are being assessed when more detailed information becomes available. Bachu (2015), Gorecki et al. (2015) and Thibeau et al. (2014) emphasized the fact that the oil and gas industry needed more than a hundred years to advance to secondary recovery (pressure maintenance), followed by tertiary recovery (enhanced oil recovery) and that $\mathrm{CO}_{2}$ storage may follow a similar path, optimizing to commercial scale storage (Green and Willhite, 1998).

When estimating prospective $\mathrm{CO}_{2}$ storage, regional geologic data, regional site data, and social data (defined below and detailed in Table 1) should be considered (US-DOE-NETL, 2013). Regional geologic data are analyzed to identify geologic formations suitable for storage at depths capable of maintaining $\mathrm{CO}_{2}$ in a dense state with one or more impermeable confining layers to contain the $\mathrm{CO}_{2}$ and protect Underground Sources of Drinking Water (USDW) (USDOE-NETL, 2013). Regional site data should consider any proximity issues to the storage area in terms of protected and sensitive areas, population centers, and available resources (US-DOENETL, 2013). Social data considers public implications such as land ownership, pore space ownership, permitting and approval processes, and government structures (US-DOE-NETL, 2013). Specifically, demographic trends and land use should be evaluated and considered. 
Table 1: Guidelines for Site Screening (US-DOE-NETL, 2013),

\begin{tabular}{|c|c|c|c|}
\hline COMPONENT & & EEMENT & GUIDLLINES FOA SITE SCREENANG \\
\hline \multirow{4}{*}{ 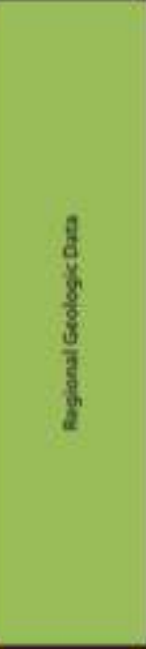 } & \multirow{4}{*}{ 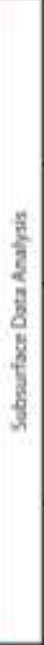 } & $\begin{array}{c}\text { Injectien } \\
\text { formatien(s) }\end{array}$ & 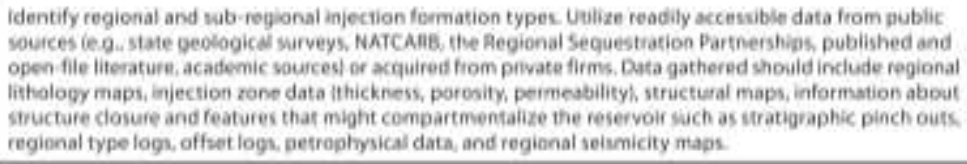 \\
\hline & & $\begin{array}{l}\text { Adequate } \\
\text { Dopah }\end{array}$ & 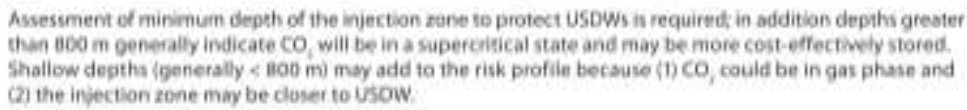 \\
\hline & & $\begin{array}{l}\text { Confining } \\
\text { Zane }\end{array}$ & 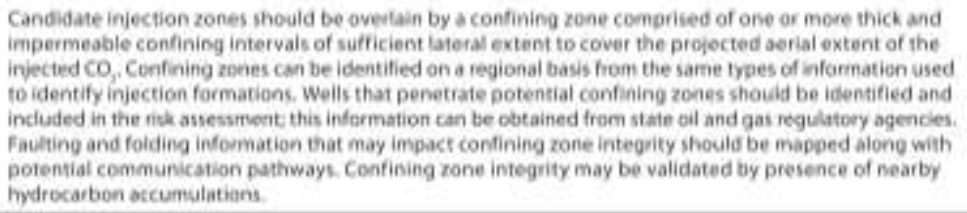 \\
\hline & & $\begin{array}{l}\text { Prospective } \\
\text { Storage } \\
\text { Pesources }\end{array}$ & 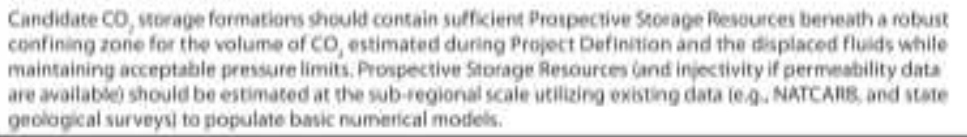 \\
\hline \multirow{4}{*}{$\begin{array}{l}\frac{9}{2} \\
\frac{8}{3} \\
\frac{1}{3} \\
\frac{1}{2}\end{array}$} & \multirow{4}{*}{ 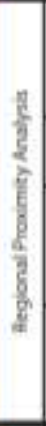 } & $\begin{array}{l}\text { Pretected and } \\
\text { Sensitive Areas }\end{array}$ & 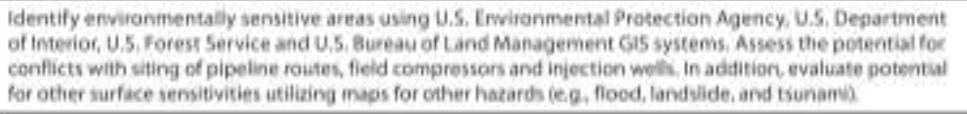 \\
\hline & & $\begin{array}{l}\text { Population } \\
\text { Centers }\end{array}$ & $\begin{array}{l}\text { Identify population centers using state and federal census data. Assess the potential for conflicts with siting } \\
\text { of carban stonge peopects. }\end{array}$ \\
\hline & & $\begin{array}{l}\text { fvisting } \\
\text { nesource } \\
\text { Develogment }\end{array}$ & 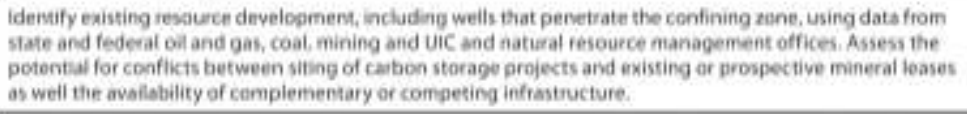 \\
\hline & & Pipeine hoWs & 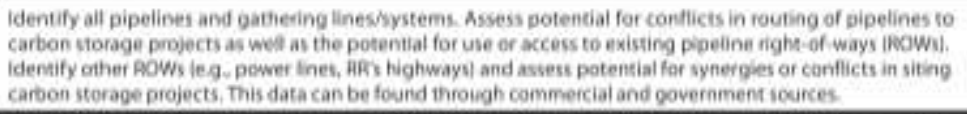 \\
\hline \multirow{2}{*}{$\frac{d}{\frac{d}{3}}$} & \multirow{2}{*}{$\begin{array}{l}\frac{2}{2} \\
\frac{2}{2} \\
\frac{8}{8} \\
\frac{3}{8} \\
\frac{3}{8}\end{array}$} & $\begin{array}{c}\text { Oenogographic } \\
\text { Trendi }\end{array}$ & 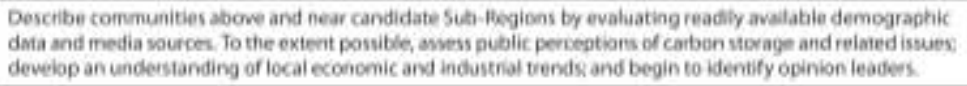 \\
\hline & & $\begin{array}{l}\text { Land Use: } \\
\text { Industrial and } \\
\text { Environmental } \\
\text { History }\end{array}$ & 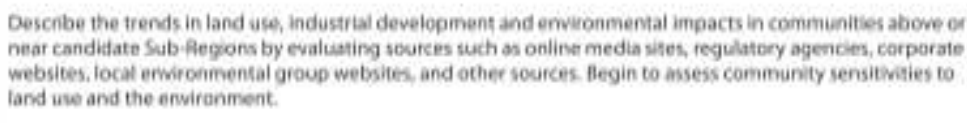 \\
\hline $\begin{array}{l}\text { Complete Site } \\
\text { Screening }\end{array}$ & & Selected Mrea & Develep a list of potential Selected Aveas and rank based on citeria established in Project Definition. \\
\hline
\end{tabular}


Data availability and specificity vary considerably from very large regional assessments down to selected areas that may be developed for commercial storage. While the framework for the volumetric equation and screening criteria are similar, the level of detail, data availability, and data sources at a selected area will be much greater than what is available for very large regions. For regional estimates, geologic data are typically limited, unavailable, or poorly distributed creating inherent uncertainty. Assumptions must be made regarding formation and petrophysical properties either from sparse, location-specific geophysical data or by geostatistical extrapolation from regional or national data. As selected areas and formations are identified, prospective resource estimates will be refined based on confirmation of existing data analysis and enhanced with additional subsurface geologic data analyzed by advanced geologic and geostatistical techniques.

\section{Methodology vs. Method}

The distinction between a methodology and a method is important for the purposes of this paper. A methodology is a body of methods, rules, and conceptual modes of thinking that provide the theoretical basis underlying an analysis. By comparison, a method is a particular application of a methodology, with a specific and defined algorithm for computing a particular number. For example, the US-DOE-NETL resource estimation methodology for saline formations is a volumetric analysis, meaning that it is based on estimating the fraction of a given volume that can be filled with $\mathrm{CO}_{2}$ while the method consists of a specific equation with specific geologic terms and efficiency values determined in a specific manner that are applied to estimate prospective storage (Goodman et al., 2011). 


\section{US-DOE-NETL Methodology and Method for Screening Potential Regions and Sub- Regions}

The US-DOE methodology and method is detailed in a previous paper and describes how to screen potential sub-regions, such as a sedimentary basin, by estimating the $\mathrm{CO}_{2}$ prospective storage resource (Goodman et al., 2011). The method is intended to be applied to a region of interest when subsurface geologic data are sparse and limited. The total pore volume available for $\mathrm{CO}_{2}$ storage is estimated by using average values for geologic properties such as total formation area, gross thickness, and total porosity. An efficiency factor is applied to gauge the fraction of the total pore volume that will be accessible to $\mathrm{CO}_{2}$ storage at a regional to national scale.

For $\mathrm{CO}_{2}$ storage, the region selected will contain saline formations which are composed of water-saturated, porous rock sealed by one or more regionally extensive low-permeability caprock formations. A saline aquifer is defined by the EPA as containing formation water with a total dissolved solids (TDS) content greater than 10,000 parts per million or ppm (EPA, 2010). The region defined for $\mathrm{CO}_{2}$ storage may include one or multiple formations. Even with limited geologic characterization, there is a reasonable degree of confidence that the selected region will meet the following criteria: (1) pressure and temperature conditions in the saline formation are adequate to keep the $\mathrm{CO}_{2}$ in a supercritical state, which requires hydrostatic pressures that typically occur at or below a depth of 800 meters; (2) a suitable seal system, such as a caprock, is present to limit vertical flow of the $\mathrm{CO}_{2}$ to the surface; and (3) a combination of hydrogeologic boundary and low flow conditions will isolate the $\mathrm{CO}_{2}$ within the saline formation as a limited plume. 
The volumetric approach to estimate prospective mass $\mathrm{CO}_{2}$ storage resource $\left(G_{\mathrm{CO} 2}\right)$ for geologic storage in saline formations is described by Equation 1 and Table 2:

$$
G_{C O 2}=A_{t} h_{g} \phi_{t} \rho E_{\text {saline }}
$$

In this approach, geologic data are assumed to be limited, thus the total area $\left(A_{t}\right)$, gross thickness $\left(h_{g}\right)$, and total porosity $\left(\phi_{t}\right)$ of the formation are multiplied to account for the total bulk volume of pore space available (Equation 1 and Table 2) (Goodman et al., 2011). $\mathrm{CO}_{2}$ density $(\rho)$ is estimated at storage depth using temperature and pressure and converts the $\mathrm{CO}_{2}$ reservoir volume to mass. At this level of screening, average, deterministic values for $A_{t}, h_{g}, \phi_{t}$, and $\rho$ are applied in the equation. Storage efficiency $\left(E_{\text {saline }}\right)$ reduces the total pore volume that will be accessible to $\mathrm{CO}_{2}$ storage at a regional to national scale. Efficiency factors were estimated by stochastic methods for the following three lithologic classes: clastics, dolomites, and limestones and range between 0.40 and 5.5 percent over the $10^{\text {th }}$ to $90^{\text {th }}$ percent probability range. It is important to note that efficiency factors are not solely dependent upon lithology and that other factors such as depositional environment, formation structure, formation depth, and other parameters need to be considered when estimating storage efficiency (Blondes et al., 2013), (Szulczewski and Juanes, 2009).

Table 2: Definition of parameters used in Equation 1 for estimating prospective $\mathrm{CO}_{2}$ storage resources in saline formations for potential regions and sub-regions (Goodman et al., 2011).

\begin{tabular}{|c|c|c|}
\hline Parameter & Units $^{*}$ & Description \\
\hline $\mathrm{G}_{\mathrm{CO} 2}$ & $\mathrm{M}$ & Mass estimate of saline formation $\mathrm{CO}_{2}$ storage resource. \\
\hline
\end{tabular}




\begin{tabular}{|c|c|l|}
\hline$A_{t}$ & $\mathrm{~L}^{2}$ & $\begin{array}{l}\text { Geographical area that defines the basin or region being } \\
\text { assessed for } \mathrm{CO}_{2} \text { storage. }\end{array}$ \\
\hline $\mathrm{h}_{\mathrm{g}}$ & $\mathrm{L}$ & $\begin{array}{l}\text { Gross thickness of saline formations for which } \mathrm{CO}_{2} \text { storage is } \\
\text { assessed within the basin or region defined by } \mathrm{A}_{\mathrm{t}} .\end{array}$ \\
\hline$\phi_{t}$ & $\mathrm{~L}^{3} / \mathrm{L}^{3}$ & Total porosity in volume defined by the net thickness. \\
\hline$\rho$ & $\mathrm{M} / \mathrm{L}^{3}$ & $\begin{array}{l}\text { Density of } \mathrm{CO}_{2} \text { evaluated at pressure and temperature that } \\
\text { represents storage conditions anticipated for a specific } \\
\text { geologic unit averaged over } \mathrm{h}_{\mathrm{g}} \text { and } \mathrm{A}_{\mathrm{t}} .\end{array}$ \\
\hline E & $\mathrm{L} \mathrm{L}^{3} / \mathrm{L}^{3}$ & $\begin{array}{l}\mathrm{CO}_{2} \text { storage efficiency factor that reflects a fraction of the } \\
\text { total pore volume that is filled by } \mathrm{CO}_{2} .\end{array}$ \\
\hline
\end{tabular}

* $\mathrm{L}$ is length; $\mathrm{M}$ is mass.

\section{US-DOE-NETL Methodology and Method for Screening Selected Areas}

\subsection{Methodology for Selected Areas}

As presented here, the refined US-DOE-NETL methodology for selected areas, such as a formation, identifies pore space available for $\mathrm{CO}_{2}$ storage based on increased data availability and advanced geologic interpretation. The volumetric approach to estimate prospective mass $\mathrm{CO}_{2}$ storage resource $(G)$ of the selected area, such as a formation, is described by Equations 2 and 3 and Table 3:

$$
G=A^{d} h^{s} \phi^{s} \rho^{s} E_{\text {saline }}{ }^{s}
$$

and

$$
E_{\text {saline }}{ }^{s}=E_{A}{ }^{s} E_{h}{ }^{s} E_{\phi}{ }^{s} E_{V}{ }^{s} E_{d}{ }^{s} .
$$

Superscripts (d) and (s) are used herein to denote whether a variable is treated deterministically (d) or stochastically (s). In this approach, geologic data are assumed to be available, allowing variables with sufficient data to be treated stochastically and be defined by the data available. 
Area $\left(A^{d}\right)$ defines the geographical area of the formation that will be assessed for $\mathrm{CO}_{2}$ storage, thickness $\left(h^{s}\right)$ defines the thickness of the formation for $\mathrm{CO}_{2}$ storage defined by $\left(A^{d}\right)$, and porosity $\left(\phi^{S}\right)$ is the pore space in the formation defined by $\left(A^{d}\right) . \mathrm{CO}_{2}$ density $\left(\rho^{S}\right)$ is evaluated at pressure and temperature that represents storage conditions for $A^{d}$ and $h^{s}$. Storage efficiency $\left(E_{\text {saline }}{ }^{s}\right.$ ) reflects a fraction of the total pore volume that is filled by $\mathrm{CO}_{2}$. The net-to-total area term $\left(E_{A}{ }^{s}\right)$ represents the fraction of the geologic area accessible for $\mathrm{CO}_{2}$ storage at the top of the formation, the net-to-gross thickness $\left(E_{h}{ }^{s}\right)$ term represents the fraction of thickness of the formation of interest that will be accessible for $\mathrm{CO}_{2}$ storage, the effective-to-total porosity $\left(E_{\phi}{ }^{s}\right.$ ) term represents the fraction of total porosity that can effectively store $\mathrm{CO}_{2}$, the volumetric displacement $\left(E_{V}{ }^{s}\right)$ term represents the combined fraction of immediate volume surrounding an injection well that can be contacted by $\mathrm{CO}_{2}$ and the fraction of net thickness that is contacted by $\mathrm{CO}_{2}$ as a consequence of the density difference between $\mathrm{CO}_{2}$ and in-situ water, and the microscopic displacement term $\left(E_{d}{ }^{S}\right)$ represents the fraction of pore space unavailable due to immobile in-situ fluids which is typically residual water saturation.

In this refined method for selected areas, such as a formation, $A^{d}$ is treated deterministically and $h^{s}, \phi^{s}, \rho^{s}$, and $E_{\text {saline }}{ }^{s}$ are treated stochastically. For $h^{s}, \phi^{s}$, and $\rho^{s}$ the mean and standard deviation are calculated based on available geologic data and an appropriate distribution is selected that best represents the geologic interpretation (SPE/WPC, 2001). Storage efficiency $\left(E_{\text {saline }}{ }^{s}\right)$ is estimated by Monte Carlo sampling where $E_{A}{ }^{s}, E_{h}{ }^{s}, E_{\phi}{ }^{s}, E_{V}{ }^{s}$, and ${E_{d}}^{s}$ are based on geologic properties of the formation instead of extrapolated values from national or regional data. 
Table 3 Definition of parameters used in Equations 2 and 3 for estimating prospective $\mathrm{CO}_{2}$ storage resources in saline formations for selected areas

\begin{tabular}{|c|c|}
\hline Parameter & Description \\
\hline$G$ & Mass estimate of saline formation $\mathrm{CO}_{2}$ storage resource. \\
\hline$A^{d}$ & Geographical area that defines the formation being assessed for $\mathrm{CO}_{2}$ storage. \\
\hline$h^{s}$ & $\begin{array}{l}\text { Thickness of saline formation for which } \mathrm{CO}_{2} \text { storage is assessed as defined } \\
\text { by } A^{d} \text {. }\end{array}$ \\
\hline$\phi^{s}$ & Porosity is the volume of void space per volume of rock \\
\hline$\rho^{s}$ & $\begin{array}{l}\text { Density of } \mathrm{CO}_{2} \text { evaluated at pressure and temperature that represents storage } \\
\text { conditions anticipated for a specific geologic unit averaged over } \\
h^{s} \text { and } A^{d} \text {. }\end{array}$ \\
\hline$E_{\text {saline }}{ }^{s}$ & $\begin{array}{l}\mathrm{CO}_{2} \text { storage efficiency factor that reflects a fraction of the total pore volume } \\
\text { that is filled by } \mathrm{CO}_{2} \text {. }\end{array}$ \\
\hline \multicolumn{2}{|c|}{ Geologic terms used to define the selected area pore volume } \\
\hline$E_{A}{ }^{s}$ & $\begin{array}{l}\text { Net-to-Total Area: Fraction of the geologic area accessible for } \mathrm{CO}_{2} \text { storage at } \\
\text { the top of the formation }\end{array}$ \\
\hline$E_{h}{ }^{s}$ & $\begin{array}{l}\text { Net-to-Gross Thickness: Fraction of thickness of the formation of interest } \\
\text { that will be accessible for } \mathrm{CO}_{2} \text { storage }\end{array}$ \\
\hline$E_{\phi}^{s}$ & $\begin{array}{l}\text { Effective-to-Total Porosity: fraction of total porosity that can effectively } \\
\text { store } \mathrm{CO}_{2}\end{array}$ \\
\hline \multicolumn{2}{|c|}{$\begin{array}{l}\text { Displacement terms used to define the pore volume immediately surrounding a single } \\
\text { well } \mathrm{CO}_{2} \text { injector. }\end{array}$} \\
\hline$E_{V}{ }^{s}$ & $\begin{array}{l}\text { Volumetric Displacement Efficiency: Combined fraction of immediate } \\
\text { volume surrounding an injection well that can be contacted by } \mathrm{CO}_{2} \text { and the } \\
\text { fraction of net thickness that is contacted by } \mathrm{CO}_{2} \text { as a consequence of the } \\
\text { density difference between } \mathrm{CO}_{2} \text { and in-situ water }\end{array}$ \\
\hline$E_{d}^{s}$ & $\begin{array}{l}\text { Microscopic Displacement Efficiency: Fraction of pore space unavailable } \\
\text { due to immobile in-situ fluids (typically residual water saturation) }\end{array}$ \\
\hline
\end{tabular}


For selected areas (i.e. a formation) - area, thickness, and porosity can be constrained by more detailed geologic interpretation such as identifying zones of higher porosity within the formation and the presence of low porosity zones occluded by secondary minerals or non-mobile fluid saturation. The area $\left(A^{d}\right)$ of the potential storage unit is treated deterministically and should be well defined at this phase of a $\mathrm{CO}_{2}$ storage project. Thickness $\left(h^{s}\right)$ and porosity $\left(\phi^{s}\right)$ should be represented stochastically with a probability distribution (i.e. log-normal) that best represents available data and geologic interpretation. Thickness and porosity data points may not be evenly distributed across the formation and may be spatially grouped, requiring the use of geostatistics to interpolate between data points (Jensen et al., 2000; Diggle and Ribeiro Jr., 2007; Webster and Oliver, 2007; Brennan et al., 2010). Oil and gas industry guidance on selecting distribution functions, recommends that distribution choice be based on the best fit to the geologic data (SPEE, 1988, 2001). Normal, lognormal, or other appropriate probability distributions are selected to reflect underlying uncertainty in the data. Triangular distributions are useful when data are extremely limited. A uniform distribution is applied when a probability distribution cannot be determined (SPE/WPC, 2001; Demirmen, 2007). $\mathrm{CO}_{2}$ density in the storage formation should be based on in-situ conditions of pressure and temperature and be treated stochastically (Ellis and Singer, 2008).

\subsection{Storage Efficiency}

A recent review article by Bachu (2015) summarizes the development of $\mathrm{CO}_{2}$ storage efficiency estimations in deep saline formations since 2007. Storage efficiency represents the pore space accessible to $\mathrm{CO}_{2}$. Not all pore space will come in contact with $\mathrm{CO}_{2}$ or be saturated by $\mathrm{CO}_{2}$ due to geologic heterogeneity, and occupied pore volume depends on properties of the 
storage formation and seal, storage operations, and regulatory and legal constraints. Efficiency factors also vary temporally and spatially, and it is important to note that the scale of the assessment also affects the storage efficiency. When screening large regions or sub-regions, efficiency factors are smaller as the region of interest is not well characterized. For selected areas and specific sites, efficiency factors will approach 1 as more detailed geologic analysis and tools are available to screen portions amenable to $\mathrm{CO}_{2}$ storage and reductions in pore volume are incorporated in storage parameters $A^{d}, h^{s}$, and $\phi^{s}$ rather than corresponding efficiency factors. In general, efficiency factors should be based on documented geologic interpretation as there is not a standard set of efficiency factors available. Bachu (2015) concluded that storage efficiency values have a large range, between $<1$ to $>10 \%$.

In US-DOE-NETL storage methods, storage efficiency is estimated after $\mathrm{CO}_{2}$ injection is completed by a log odds approach using Monte Carlo sampling where the low and high estimated probability values are based on the $\mathrm{P}_{10}$ and $\mathrm{P}_{90}$ confidence interval (Goodman et al., 2011). Statistical inputs to predict appropriate ranges for efficiency factors are currently available from the database created by the International Energy Agency (IEA) (GHG, 2009). This database supplies ranges of variables needed to calculate storage efficiency for different lithologies and depositional environments based on numerical simulations of oil and gas reservoir field data. It is important to note that while statistical ranges for efficiency factors are available for lithology and depositional environment, other factors such as geologic structure (i.e. anticlines, synclines, and domes), formation depth, and other parameters need to be considered when estimating prospective storage resources. It is best to rely on intrinsic geologic properties when assigning statistical ranges for storage efficiency. 
For selected areas, the efficiency term ${E_{A}}^{s}$ includes any processes or limiting criteria that occur on the horizontal scale, while the vertical efficiency term, $E_{h}{ }^{s}$, incorporates any vertical processes. Porosity efficiency $\left(E_{\phi}{ }^{s}\right)$ modifies porosity for the selected area. The efficiency term $E_{A}{ }^{S}$ represents a reduction in the available storage area from a map view perspective of the formation after considering subsurface data analysis, regional proximity analysis, and social context analysis (see Table 1) (US-DOE-NETL, 2010). Factors to consider include: injection formation type, protected and sensitive areas, population centers, existing resource development, pipeline right-of-ways, demographic trends, and land use history (see Table 1). The efficiency term, $E_{h}{ }^{s}$ represents limits placed on storage as a function of depth. Factors to consider are as follows: injection formation characteristics such as porosity and permeability heterogeneities, lithology, structure, seismicity; depth requirements for supercritical or liquid $\mathrm{CO}_{2}$ storage; and whether an adequate confining zone is present (See Table 1). These efficiency terms, therefore, include the large scale distinctions defined in Table 1 that are not already accounted for in the geologic analysis of area $\left(A^{\mathrm{d}}\right)$, thickness $\left(\mathrm{h}^{\mathrm{d}}\right)$, and porosity $\left(\phi^{\mathrm{s}}\right)$ which further reduce the volume accessible for $\mathrm{CO}_{2}$ storage.

Based on the confidence and completeness of the geologic information available for $\left(A^{d}\right)$, $\left(h^{d}\right)$, and $\left(\phi^{s}\right)$, efficiency terms for $\left(E_{A}^{s}\right),\left(E_{h}^{s}\right)$, and $\left(E_{\phi}^{s}\right)$ may not be needed. If the geologic analysis and interpretation is complete and the pore volume available to $\mathrm{CO}_{2}$ storage has been identified, the efficiency term(s) can be eliminated by assigning the appropriate factor(s) equal to one. If the geologic data set and analysis are partially complete, a user specified efficiency range may be applied for area $\left(E_{A}{ }^{s}\right)$, thickness $\left(E_{h}^{s}\right)$, and porosity $\left(E_{\phi}^{s}\right)$ based on the intrinsic geologic properties available and further geologic interpretation. 
The volumetric efficiency term $\left({E_{V}}^{s}\right)$ captures the "sweep efficiency" defined as the fraction of a given well-scale or multi-well field-scale volume efficiency relative to the ideal efficiency of perfect displacement of the connate fluid. It includes various complex processes occurring at a variety of scales including multi-well geometry and pressure management, gravity/buoyancy effects, multiphase fluid saturation gradients as a function of radial and vertical distance, porescale petrophysics, and wettability-controlled pore-scale fluid occupancy and saturation. All these processes are tied to relative permeability and fluid mobility, which are often hysteretic functions of brine drainage and post-drainage re-imbibition. The displacement efficiency term, $E_{d}{ }^{s}$, captures the fraction of the $\mathrm{CO}_{2}$ contacted, water-filled pore volume that can be replaced by $\mathrm{CO}_{2}$. Ranges for $E_{V}{ }^{s}$ and $E_{d}{ }^{s}$ should only be modified with detailed reservoir simulation results when well or field data are available.

\subsection{Method for Estimating Prospective $\mathrm{CO}_{2}$ Storage Resource of Selected Areas ( $\mathrm{CO}_{2}-\mathrm{SCREEN}$}

\section{Method and Tool)}

$\mathrm{CO}_{2}$-SCREEN $\left(\mathrm{CO}_{2}\right.$ Storage Prospective Resource Estimation Excel aNalysis) is an Excel based method and tool developed by the US-DOE-NETL to screen geologic formations by applying the aforementioned refined US-DOE-NETL methodology for selected areas (Sanguinito et al., 2016). $\mathrm{CO}_{2}$-SCREEN is a tool designed to calculate prospective $\mathrm{CO}_{2}$ storage resources for geologic formations from very large regional assessments down to selected areas that may be developed for commercial storage. This tool provides an interactive version of the US-DOE methodology described in this paper for refining prospective $\mathrm{CO}_{2}$ storage resource in saline formations based on increased data availability and advanced geologic interpretation. $\mathrm{CO}_{2^{-}}$ SCREEN is free and available for public use and can be accessed live on the NETL Energy Data 
eXchange (EDX) website (https://edx.netl.doe.gov/organization/co2-screen) (Sanguinito et al., 2016).

$\mathrm{CO}_{2}$-SCREEN is comprised of two files: an Excel file used for inputs and outputs and a GoldSim Player file used to run Monte Carlo simulations. The Excel file allows a user to input subsurface geological physical parameter values, establish ranges for storage efficiency factors and set various formation-related parameters corresponding to depositional environments and intrinsic formation properties. The GoldSim Player file accesses the saved input data in the Excel file, calculates probability estimates for $\mathrm{CO}_{2}$ storage using Monte Carlo methods, and outputs these values back into the Excel file.

The following is a brief example of how to use the $\mathrm{CO}_{2}$-SCREEN tool but users are encouraged to see Sanguinito et al., (2016) for a comprehensive guide on using $\mathrm{CO}_{2}$-SCREEN and its capabilities. An example input scenario for a synthetic formation named the Example Formation is shown in Figure 1. The first step in using $\mathrm{CO}_{2}$-SCREEN is entering general information (Fig. 1, Box 1). Next, a user has the option of choosing a lithology and depositional environment associated with their formation. Here, a clastics lithology and shallow shelf depositional environment are chosen for the Example Formation (Fig 1, Box 2). This choice auto-populates $\mathrm{P}_{10}$ and $\mathrm{P}_{90}$ values for all five efficiency factors based on ranges calculated by the IEA (GHG, 2009). Users have the option of forgoing the auto-populated values and inputting their own $\mathrm{P}_{10}$ and $\mathrm{P}_{90}$ ranges for the storage efficiency factors. Finally, the user enters physical parameter data (Fig. 1, Box 3). The Example Formation was divided into four grids to account for geologic heterogeneity within the formation. Users have the ability to divide their formation between 1 and 300 grids based on the formation's geologic heterogeneity and user's preference. 
The results for the Example Formation generated from the GoldSim Player are shown in Figure

2. Results are displayed as $\mathrm{P}_{10}, \mathrm{P}_{50}$, and $\mathrm{P}_{90}$ values for mass $\mathrm{CO}_{2}$ in megatons for each grid.

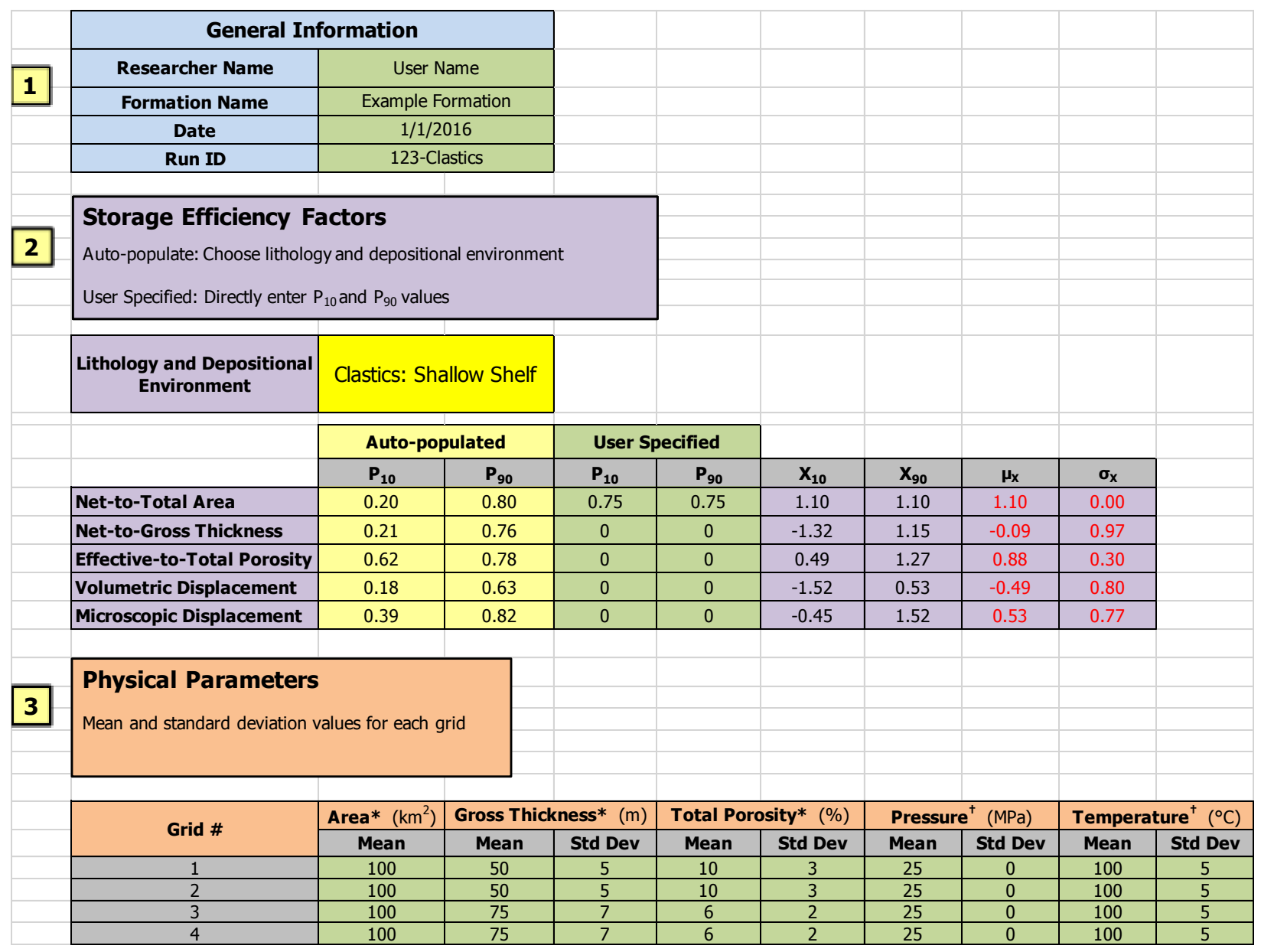

Figure 1. Inputs tab displaying data for the Example Formation example in $\mathrm{CO}_{2}$-SCREEN 


\begin{tabular}{|c|c|c|c|c|c|c|c|c|}
\hline \multicolumn{5}{|c|}{ Prospective $\mathrm{CO}_{2}$ Storage Resource } & \multirow{2}{*}{$\frac{\text { Grid }}{1}$} & \multirow{2}{*}{ P10 } & \multirow{2}{*}{$\begin{array}{l}\text { P50 } \\
14.189\end{array}$} & \multirow{2}{*}{$\frac{\text { P90 }}{37.453}$} \\
\hline & & & & & & & & \\
\hline & & & & & 2 & 4.380 & 14.140 & 36.725 \\
\hline Information & & & & & 3 & 3.734 & 12.682 & 33.592 \\
\hline & & & & & 4 & 3.839 & 12.559 & 33.460 \\
\hline Researcher Name & \multicolumn{2}{|c|}{ Jane Doe } & & & 5 & 0.000 & 0.000 & 0.000 \\
\hline Formation Name & \multicolumn{2}{|c|}{ Example Formation } & & & 6 & 0.000 & 0.000 & 0.000 \\
\hline Date & \multicolumn{2}{|c|}{$5 / 27 / 2016$} & & & 7 & 0.000 & 0.000 & 0.000 \\
\hline Depositional Environment & \multicolumn{2}{|c|}{ Clastics: Shallow Shelf } & & & 8 & 0.000 & 0.000 & 0.000 \\
\hline \multirow[t]{2}{*}{ Number of Grids } & \multicolumn{2}{|c|}{4} & & & 9 & 0.000 & 0.000 & 0.000 \\
\hline & & & & & 10 & 0.000 & 0.000 & 0.000 \\
\hline \multirow[t]{2}{*}{$\mathrm{CO}_{2}$ Storage Statistics } & & & & & 11 & 0.000 & 0.000 & 0.000 \\
\hline & P10 & P50 & P90 & & 12 & 0.000 & 0.000 & 0.000 \\
\hline Summed $\mathrm{CO}_{2}$ Total & 16.29 & 53.57 & 141.23 & Mt & 13 & 0.000 & 0.000 & 0.000 \\
\hline \multirow[t]{2}{*}{ Average $\mathrm{CO}_{2}$ per Grid } & 4.07 & 13.39 & 35.31 & Mt & 14 & 0.000 & 0.000 & 0.000 \\
\hline & & & & & 15 & 0.000 & 0.000 & 0.000 \\
\hline Summed $\mathrm{CO}_{2}$ Total & 0.016 & 0.054 & 0.141 & Gt & 16 & 0.000 & 0.000 & 0.000 \\
\hline \multirow[t]{4}{*}{ Average $\mathrm{CO}_{2}$ per Grid } & 0.004 & 0.013 & 0.035 & Gt & 17 & 0.000 & 0.000 & 0.000 \\
\hline & & & & & 18 & 0.000 & 0.000 & 0.000 \\
\hline & & & & & 19 & 0.000 & 0.000 & 0.000 \\
\hline & & & & & 20 & 0.000 & 0.000 & 0.000 \\
\hline
\end{tabular}

Figure 2. The $\mathrm{CO}_{2}$ storage resource results for the Example Formation scenario in $\mathrm{CO}_{2-}$

\section{SCREEN}

\section{Summary}

Prospective $\mathrm{CO}_{2}$ resource estimation of large regions or sub-regions, such as a basin, occurs at the initial screening stages of a project using only limited publicly available geophysical data. As the scale of investigation is narrowed and selected areas and formations are identified, prospective $\mathrm{CO}_{2}$ resource estimation can be refined when site-specific geophysical data are available. This paper refines existing US-DOE-NETL methodologies and methods based on data availability when a greater level of geologic characterization is available. The methodology 
builds upon the volumetric approach previously reported at the regional scale (Goodman et al., 2011). We refined the distinctions between existing US-DOE-NETL methodologies and presented new notation that explicitly identifies differences between data availability and data sources used for geologic parameters and efficiency factors as the scale of investigation is narrowed. The refined $\mathrm{CO}_{2}$ resource estimation method is made available in a publicly available tool named $\mathrm{CO}_{2}$-SCREEN to calculate prospective $\mathrm{CO}_{2}$ storage resource (Sanguinito et al., 2016). 


\section{Acknowledgements}

This research was supported in part by appointments to the National Energy Technology Laboratory Research Participation Program, sponsored by the U.S. Department of Energy and administered by the Oak Ridge Institute for Science and Education.

\section{Disclaimer}

This report was prepared as an account of work sponsored by an agency of the United States Government. Neither the United States Government nor any agency thereof, nor any of their employees, makes any warranty, express or implied, or assumes any legal liability or responsibility for the accuracy, completeness, or usefulness of any information, apparatus, product, or process disclosed, or represents that its use would not infringe privately owned rights. Reference herein to any specific commercial product, process, or service by trade name, trademark, manufacturer, or otherwise does not necessarily constitute or imply its endorsement, recommendation, or favoring by the United States Government or any agency thereof. The views and opinions of authors expressed herein do not necessarily state or reflect those of the United States Government or any agency thereof. 


\section{References}

Bachu, S., 2008. CO2 storage in geological media: role, means, status and barriers to deployment. Progr. Energy Combust. Sci. 34, 254-273.

Bachu, S., 2015. Review of CO2 storage efficiency in deep saline aquifers International Journal of Greenhouse Gas Control 40, 188-202.

Blondes, M.S., Brennan, S.T., Merrill, M.D., Buursink, M.L., Warwick, P.D., Cahan, S.M., Cook, T.A., Corum, M.D., Craddock, W.H., DeVera, C.A., Drake, R.M., Drew, L.J., Freeman, P.A., Lohr, C.D., Olea, R.A., Roberts-Ashby, T.L., Slucher, E.R., Varela, B.A., 2013. National assessment of geologic carbon dioxide storage resources-methodology implementation. U.S. Geological Survey.

Brennan, S.T., Burruss, R.C., Merrill, M.D., Freeman, P.A., Ruppert, L.F., 2010. A Probabilistic Assessment Methodology for the Evaluation of Geologic Carbon Dioxide Storage. U.S. Geological Survey, pp. 1-31.

Burruss, R.C., Brennan, S.T., Freeman, P.A., Merrill, M.D., Ruppert, L.F., Becker, M.F., Herkelrath, W.N., Kharaka, Y.K., Neuzil, C.E., Swanson, S.M., Cook, T.A., Klett, T.R., Nelson, P.H., Schenk, C.J., 2009. Development of a probabilisitic assessment methodology for evaluation of carbon dioxide storage. U.S. Geological Survey pp. 1-81.

Demirmen, F., 2007. Reserves Estimation: The Challenge for the Industry. Journal of Petroleum Technology, 80-89.

Diggle, P.J., Ribeiro Jr., P.J., 2007. Model-based Geostastics. Springer, New York City, New York.

Ellett, K.Z., Q ; Medina, C ; Rupp, J ; Wang, GC; Carr, T 2013. Uncertainty in regional-scale evaluation of $\mathrm{CO} 2$ geologic storage resources-comparison of the Illinois Basin (USA) and the Ordos Basin (China) Energy Procedia 37, 5151-5159.

Ellis, D.V., Singer, J.M., 2008. Well Logging for Earth Scientist, 2nd ed. Springer, Netherlands. 
EPA, 2010. Safe Drinking Water Act, Office of Ground Water \& Drinking Water, http://www.epa.gov/safewater/sdwa.

Frailey, S., M., Finley, R., 2009, Classification of $\mathrm{CO}_{2}$ Geologic Storage: Resource and Capacity, Energy Procedia, GHGT-9, p. 2623-2630

GHG, I., 2009. Development of Storage Coefficients for CO2 Storage in Deep Saline Formations, IEA Greeen house Gas R\&D Programme (IEA GHG).

Goodman, A., Hakala, A., Bromhal, G., Deel, D., Rodosta, T., Frailey, S., Small, M., Allen, D., Romanov, V., Fazio, J., Huerta, N., McIntyre, D., Kutchko, B., Guthrie, G., 2011. U.S. DOE methodology for the development of geologic storage potential for carbon dioxide at the national and regional scale. International Journal of Greenhouse Gas Control. International Journal of Greenhouse Gas Control 5, 952-965.

Goodman, A., Bromhal, G., Strazisar, B., Rodosta, T., Guthrie, W.F., Allen, D., Guthrie, G., 2013. Comparison of methods for geologic storage of carbon dioxide in saline formations International Journal of Greenhouse Gas Control 118, 329-342.

Gorecki, C.D., Ayash, S.C., Liu, G., 2015. A comparison of volumetric and dynamic CO2 storage resource and efficiency in deep saline formations International Journal of Greenhouse Gas Control 42, 213-225.

Green, D. W., Willhite, G. P. 1998. Enhanced Oil Recovery, Society of Petroleum Engineers Inc., Richardson, Texas.

Jensen, J.L., Lake, L.W., Corbett, P.W.M., Goggin, D.J., 2000. Statistics for petroleum engineers and geoscientists, 2nd ed. Elsevier, Amsterdam.

Levine, J.S., Fukai, I., Soeder, D.J., Bromhal, G., Dilmore, R.M., Guthrie, G.D., Rodosta, T., Sanguinito, S., Frailey, S., Gorecki, D., Peck, W., Goodman, A.L., 2016. U.S. DOE NETL Methodology for Estimating the Prospective CO2 Storage Resource of Shales at the National and Regional Scale. International Journal of Greenhouse Gas Control. 
Liu, F., Ellett, K., Xiao, Y., Rupp, J., 2013. Assessing the feasibility of CO2 storage in the New Albany Shale (Devonian-Mississippian) with potential for enhanced gas recovery using reservoir simulation. International Journal of Greenhouse Gas Control 17, 111-126.

Peck, W., Glazewski, K., Klenner, R., Gorecki, C., Steadman, E., Harju, J., 2014. A workflow to determine $\mathrm{CO} 2$ storage potential in deep saline formations. Energy Procedia 63, 5231-5238.

Sanguinito, S., Goodman, A., Levine, J.S., 2016. NETL CO2 Storage prospeCtive Resource Estimation Excel aNalysis (CO2-SCREEN) User's Manual, CO2-SCREEN, NETL's Energy Data Exchange, p. 31.

SPE/WPC, 2001. Guidelines for the Evaluation of Petroleum Reserves and Resources, Society of Petroleum Engineers Formation Evaluation. Society of Petroleum Engineers, Richardson, TX 75080-2040 USA, p. 141.

SPEE, 1988. Guildlines for Applications of Petroleum Reserves Definitions. Society of Petroleum Evaluation Engineers.

SPEE, 2001. Guidelines for the Evaluation of Petroleum Reserves and Resources. Society of Petroleum Evaluation Engineers, Richardson, TX.

Szulczewski, M., Juanes, R., 2009. A simple but rigorous model for calculating CO2 storage capacity in deep saline aquifers at the basin scale. Energy Procedia 1, 3307-3314.

Szulczewski, M.L., MacMinn, C.W., Herzog, H.J., Juanes, R., 2012. Lifetime of carbon capture and storage as a climate-change mitigation technology. Proc. Natl. Acad. Sci. U. S. A. 109 5185-5189

Thibeau, S., Bachu, S., Birkholzer, J.T., Holloway, S., Neele, F., Zhou, Q., 2014. Using pressure and volumetric approaches to estimate $\mathrm{CO} 2$ storage capacity in deep saline aquifers. Energy Procedia 63, 5294-5304.

US-DOE-NETL, 2007. Carbon Sequestration Atlas of the United States and Canda. U.S. Deparment of Energy - National Energy Technology Laboratory - Office of Fossil Energy 
US-DOE-NETL, 2008. Carbon Sequestration Atlas of the United State and Canada, second edition. U.S. Deparment of Energy - National Energy Technology Laboratory - Office of Fossil Energy

US-DOE-NETL, 2010. Carbon Sequestration Atlas of the United State and Canada, third edition U.S. Deparment of Energy - National Energy Technology Laboratory - Office of Fossil Energy

US-DOE-NETL, 2012. The United States 2012 Carbon Utilization and Storage Atlas, Fourth Edition. U.S. Deparment of Energy - National Energy Technology Laboratory - Office of Fossil Energy.

US-DOE-NETL, 2013. Site Screening, Selection and Characterization for Storage of CO2 in Deep Geologic Formations.

US-DOE-NETL, 2015. Carbon Storage Atlas, 5th Edition. U.S. Deparment of Energy - National Energy Technology Laboratory - Office of Fossil Energy.

Webster, R., Oliver, M.A., 2007. Geostatistics for Environmental Scientists, 2nd ed. Wiley, England.

Zhou, Q., Birkholzer, J.T., Tsang, C.-F., Rutqvist, J., 2008. A method for quick assessment of $\mathrm{CO} 2$ storage capacity in closed and semi-closed saline formation. International Journal of Greenhouse Gas Control 2, 626-639. 